\title{
PEMANFAATAN KITOSAN DALAM DAUR ULANG AIR SEBAGAI APLIKASI TEKNIK PRODUKSI BERSIH
}

\author{
Anggun Ratnawulan ${ }^{1 \star}$, Erliza Noor ${ }^{2}$, Pipih Suptijah ${ }^{3}$ \\ ${ }^{1}$ Program Studi Pengelolaan Sumberdaya Alam dan Lingkungan, Sekolah Pascasarjana, \\ Institut Pertanian Bogor \\ ${ }^{2}$ Departemen Teknologi Industri Pertanian, Fakultas Teknologi Pertanian, Institut Pertanian Bogor \\ ${ }^{3}$ Departemen Teknologi Hasil Perairan, Fakultas Perikanan dan Ilmu Kelautan, Institut Pertanian Bogor \\ Jalan lingkar akademik kampus Institut Pertanian Bogor Dramaga, 16680. Telepon/fax. 0251-8332779 \\ *Korespondensi: anggunratnawulan@gmail.com \\ Diterima: 06 Juni 2017/ Disetujui: 20 Juli 2018
}

Cara sitasi: Ratnawulan A, Noor E, Suptijah P. 2018. Pemanfaatan kitosan dalam daur ulang air sebagai aplikasi teknik produksi bersih. Jurnal Pengolahan Hasil Perikanan Indonesia. 21(2): 276-286.

\begin{abstract}
Abstrak
Industri pengolahan udang merupakan salah satu industri yang aktivitasnya menggunakan air dalam jumlah besar. Kuantitas dan efisiensi penggunaan air di industri tersebut sampai dengan saat ini belum mendapat perhatian serius oleh pihak manajemen bila dibandingkan dengan perhatian terhadap mutu dan kualitas air yang digunakan. Produksi bersih menawarkan suatu strategi yang bersifat solutif untuk meminimalisir dan mengefisiensikan penggunaan sumberdaya air dan turut serta membantu pengelolaan lingkungan. Tujuan dari penelitian ini adalah menentukan tingkat konsentrasi biokoagulan kitosan dalam daur ulang air limbah pencucian udang, kelayakan ekonomi dan manfaatnya bagi lingkungan. Penelitian ini secara teknis dilakukan dengan metode jar test, yaitu melalui proses koagulasi - flokulasi dan absorbsi dengan konsentrasi kitosan 5 ppm, 10 ppm, 15 ppm, dan 20 ppm. Paramater yang diamati meliputi Biochemical Oxygen Demand (BOD), Chemical Oxygen Demand (COD), Total Suspended Solid (TSS), warna, kekeruhan, Total Dissolved Solids (TDS), dan total coliform. Kelayakan ekonomi dilakukan melalui analisis B/C Ratio dan Payback periode, serta analisis lingkungan dilakukan secara deskriptif. Hasil penelitian menunjukkan bahwa pada konsentrasi larutan kitosan sebesar 15 ppm dengan dua kali proses koagulasi-flokulasi dan melalui absorbsi kitosan serpihan 15 gram, efektif mengubah air limbah menjadi air bersih. Kitosan secara signifikan dapat menurunkan BOD 76\%, COD 86\%, TSS 61\%, warna 85\%, kekeruhan $89 \%$, TDS $10 \%$, dan total coliform. Penggunaan kitosan sebagai bahan daur ulang air layak secara ekonomi dilihat dari nilai B/C Ratio lebih dari 1, memiliki nilai Payback periode 4 bulan, dan secara lingkungan dapat menghemat penggunaan sumberdaya air.
\end{abstract}

Kata kunci: air limbah pencucian udang, biokoagulan, efisiensi air, kualitas air

\section{Utilization of Chitosan on Recycled Water as Application of the Cleaner Production Technique}

\begin{abstract}
Shrimp processing industry uses large quantities of water for their activity. The quantity and efficiency of water used in the industry have not received serious concern by the management, when it compared with the concern of quality of water used. Cleaner production offers a solutive strategy to minimize and streamline the use of water resources and contributes to the environmental management. Thus, the purpose of this research was to determine the concentration level of chitosan biocoagulant in recycling shrimp washing wastewater as well as economic feasibility and its benefits to the environment. This research was technically carried out with the jar test method, by coagulation - flocculation and absorption process with chitosan concentration of $5 \mathrm{ppm}, 10 \mathrm{ppm}, 15 \mathrm{ppm}$, and $20 \mathrm{ppm}$, respectively. Parameters observed were Biochemical Oxygen Demand (BOD), Chemical Oxygen Demand (COD), Total Suspended Solid (TSS) color, turbidity, Total Dissolved Solids (TDS), and total coliform. Economic feasibility was carried out by B/C Ratio and Payback Periode analysis, and the environmentally by descriptive analysis. The results showed that the concentration of $15 \mathrm{ppm}$ chitosan solution with two times coagulation - flocculation process and through absorption using chitosan flakes 15 gram, effectively converting wastewater into clean
\end{abstract}


water. Chitosan significantly decreased BOD $76 \%$, COD $86 \%$, TSS $61 \%$, color $85 \%$, turbidity $89 \%$, TDS $10 \%$, and total coliform. The use of chitosan as a water recycled material is economically feasible, it showed from B/C Ratio value of more than 1, has 4 months Payback Periode, and environmentally save the use of water resources.

Keywords: biocoagulant, shrimp washing wastewater, water efficiency, water quality

\section{PENDAHULUAN}

Industri merupakan salah satu pengguna air terbesar di hampir seluruh wilayah (Nilsson et al. 2007). Industri pengolahan hasil perikanan juga menggunakan air bersih dalam jumlah banyak sebagai input utama dalam proses produksinya. Air pada industri tersebut digunakan hampir pada keseluruhan kegiatan proses produksi yang relatif kompleks, salah satunya adalah untuk pencucian bahan baku. Proses pencucian bahan baku pada industri ini dilakukan secara berulang kali guna menghindari kontaminasi bakteri, selain untuk pencucian bahan baku, air juga akan digunakan untuk pembersihan lantai ruang proses, sanitasi dan toilet (Suprihatin dan Romli 2009), dicampurkan secara langsung ke dalam bahan pangan (Rahmani 2015); dan sebagai bahan baku pembuatan es.

Penggunaan air yang besar akan menimbulkan besarnya volume limbah cair yang dihasilkan (Chowdhury et al. 2010). Hal tersebut akan berdampak pada tingginya biaya operasional yang harus dikeluarkan oleh suatu industri untuk mengolah limbah pada instalasi pengolahan air limbah (IPAL), sehingga seringkali pengolahan limbah menjadi kurang optimal (Mathukumaran dan Baskaran 2013). Penggunaan air yang ekstensif dalam pengolahan ikan selanjutnya dapat direduksi terlebih dahulu, dengan tujuan agar volume limbah yang dihasilkan dapat diminimalisir, salah satu upaya yang dapat dilakukan adalah melalui penghematan air sebagai bagian dari peluang produksi bersih pada industri pengolahan ikan (Chouwdhury et al. 2010). UNEP (2000) mendefinisikan produksi bersih sebagai penerapan strategi lingkungan yang dilakukan secara terus menerus, bersifat terpadu dan pencegahan yang dapat diterapkan pada proses, produk dan pelayanan untuk meningkatkan efisiensi secara keseluruhan dan mengurangi resiko bagi manusia dan lingkungan. Teknik produksi bersih yang dapat dilakukan dalam rangka menghemat air salah satunya adalah dengan melakukan daur ulang air (water recycle).

Beberapa penelitian menunjukkan bahwa daur ulang air pada industri pengolahan ikan dapat dilakukan dengan menggunakan berbagai macam bahan dan cara, diantaranya daur ulang air limbah peeling (pengelupasan kulit udang) dengan menggunakan sistem reverse osmosis (RO) (Cassani et al. 2006), dan daur ulang air limbah thawing dengan menggunakan sirkulasi air dengan sistem tertutup melalui proses skrining, sedimentasi/ flotasi, serta ozonisasi (Alkaya dan Demirer 2016). Penelitian lain juga menyebutkan bahwa selain dengan cara-cara tersebut, daur ulang air limbah dapat dilakukan dengan memanfaatkan limbah padat yang dihasilkan oleh industri pengolahan udang berupa kulit dan kepala udang yang telah diproses menjadi kitosan (Garcia et al. 2016).

Kitosan adalah poli-(2-amino-2-deoksi$\beta$-(1-4)-D-glukopiranosa) dengan rumus molekul $\left(\mathrm{C}_{6} \mathrm{H}_{11} \mathrm{NO}_{4}\right) \mathrm{n}$ yang diperoleh dari deasetilasi kitin (Sugita et al. 2009), yang berasal dari limbah udang berupa kulit, kepala, dan ekor yang mengandung senyawa kimia kitin (Hendrawati et al. 2015) di antaranya cangkang udang vanamei (Suptijah et al. 2011), limbah rajungan (Rochima 2007) serta ampas silase kepala udang windu (Zahiruddin et al. 2008a). Kitosan bermanfaat dalam berbagai bidang salah satunya pembentuk gel pada bakso (Nurilmala et al. 2007; Zahiruddin et al. $2008^{\mathrm{b}}$ ), pengawet filet ikan gabus (Wahyuni et al. 2013), antibakteri dalam mouthwash (Ibrahim et al. 2012), pembuatan bakto agar (Abdullah et al. 2008), serta bahan tambah beras analog (Hidayat et al. 2013).

Kitosan memiliki peranan yang baik dalam mengurangi pencemaran lingkungan, yaitu cukup efektif dalam proses penjernihan air dan air limbah (Renault et al. 2009), salah 
satunya pemurnian air sumur dengan kitosan melaui tahapan koagulasi dan filtrasi (Suptijah et al. 2008), penjernih air dan menurunkan tingkat warna, $\mathrm{pH}, \mathrm{BOD}$, dan COD (Pontinus 2016), menyerap logam berat maupun zat warna (Sugita et al. 2009; Hendrawati et al. 2015), serta efektif dalam mereduksi TSS dan COD dalam air limbah pengolahan ikan (Garcia et al. 2016). Kitosan dikenal sebagai biokoagulan alami, ramah lingkungan (Wardhani et al. 2014), terbarukan, tidak beracun, biokompatibel dan mudah mengalami biodegradasi (Renault et al. 2009; Sinardi et al. 2013; Li et al. 2016).

Penelitian ini bertujuan untuk menentukan tingkat konsentrasi biokoagulan kitosan dalam daur ulang air limbah pencucian udang, kelayakan ekonomi dan manfaatnya bagi lingkungan. Air hasil daur ulang yang diperoleh diharapkan dapat digunakan kembali untuk kegiatan operasional pada industri pengolahan udang sehingga efisiensi air dapat terwujud.

\section{BAHAN DAN METODE Bahan dan Alat}

Bahan yang digunakan dalam proses daur ulang adalah sampel air limbah pencucian udang yang diperoleh dari unit pengolahan udang di Pati Jawa Tengah, kitosan komersial dengan bahan baku kulit udang jenis black tiger (CV. Bio Chitosan Indonesia), asam asetat 2\% (Merck), dan akuades. Alat-alat yang digunakan meliputi portable flocculator FP 4 (Velp Scientifica Italy), magnetic stirrer (IKA C-MAG HS7 Malaysia), water quality meter (IP67 Combo PH/COND/SALT/DO Taiwan), TDS meter (TDS-3 USA), turbidity meter (Lutron TU-2016 Taiwan), portable data logging spectrofotometer (HACH DR/2010 USA), beaker glass (IWAKI Pyrex Japan), tabung reaksi (IWAKI Pyrex Japan), pipet (IWAKI Pyrex Japan), prototype kolom (botol air mineral, pipa paralon Maspion Indonesia, dan kain blacu sebagai saringan).

\section{Metode Penelitian \\ Pemilihan sampel}

Sampel yang digunakan berupa sampel air limbah pencucian udang. Pemilihan sampel yaitu pada air limbah pencucian bahan baku didasarkan atas adanya beberapa penelitian, yaitu Cassani et al. (2006) yang berhasil melakukan daur ulang dengan sampel air limbah peeling udang, serta Alkaya dan Demirer (2016) dengan sampel air limbah thawing udang. Pemilihan sampel pada penelitian ini juga berdasarkan data yang diperoleh dari salah satu unit pengolahan udang yang berlokasi di Pati Jawa Tengah, yang menyebutkan bahwa dari keseluruhan air yang digunakan pada proses produksi, $70 \%$ air digunakan untuk kegiatan pencucian bahan baku udang. Air limbah pencucian bahan baku merupakan salah satu sumber limbah cair industri pengolahan udang yang mempunyai karakteristik berupa kandungan bahan organik terlarut, padatan tersuspensi, serta bahan anorganik. Air limbah dapat dimanfaatkan melalui proses daur ulang atau recycle (Suprihatin dan Romli 2009).

\section{Pembuatan larutan kitosan}

Pembuatan larutan kitosan untuk dijadikan koagulan mengacu pada metode Prayudi dan Susanto (2000), yaitu dengan cara membuat larutan kitosan dengan kadar $1 \%$ dalam asetat $(\mathrm{CH} 3 \mathrm{COOH}) 2 \%$. 1 gram kitosan dalam $20 \mathrm{~mL}$ asam asetat $2 \%$ ditambahkan air suling atau akuades hingga $100 \mathrm{~mL}$ serta dilakukan pengadukan. Pengadukan dilakukan dengan menggunakan magnetic stirer untuk memastikan kitosan terlarut dengan baik dan sempurna.

\section{Koagulasi flokulasi dengan metode jar test}

Penelitian diawali dengan proses koagulasi flokulasi, yaitu dengan melakukan optimasi konsentrasi larutan kitosan pada sampel air limbah. Proses koagulasi flokulasi dilakukan dengan metode jar test menggunakan alat flokulator atau pengaduk (Muruganandam et al. 2017; MIWEA 2018). Pengadukan cepat (rapid mixing) dilakukan pada kecepatan $200 \mathrm{rpm}$ selama 1 menit, dilanjutkan dengan pengadukan lambat (slow mixing) pada kecepatan $50 \mathrm{rpm}$ selama 30 menit, setelah proses pengadukan selesai, dilakukan agitasi atau pengendapan selama 30 menit lalu disaring. Hasil penyaringan kemudian dianalisis. Proses koagulasi- 
flokulasi dilakukan melalui dua tahap percobaan sebagai berikut: air limbah pencucian bahan baku ditambahkan larutan kitosan pada rentang konsentrasi 5 ppm, 10 ppm, 15 ppm, 20 ppm, 25 ppm, serta kontrol tanpa larutan kitosan pada $500 \mathrm{~mL}$ sampel air limbah. Hasil dari koagulasi terbaik diproses kembali dengan menambahkan larutan kitosan dengan rentang konsentrasi 5 ppm, 10 ppm, 15 ppm, 20 ppm dan 25 ppm. Percobaan penambahan kembali larutan kitosan dilakukan untuk mendapatkan hasil yang lebih optimal.

\section{Absorbsi limbah dengan kolom kitosan}

Hasil penyaringan yang diperoleh dari proses koagulasi-flokulasi kemudian dilakukan proses absorbsi dengan tujuan mendapatkan hasil yang lebih optimal. Proses ini dilakukan dengan cara mengalirkan air hasil penyaringan ke dalam kolom yang terbuat dari pipa plastik transparan berisi kitosan serpihan dengan bobot 15 gram (Suptijah et al. 2008). Bobot kitosan serpihan yang digunakan sebagai absorben sekaligus filter air sesuai dengan hasil yang diperoleh pada penelitian Suptijah et al. (2008). Hasil yang didapat dari proses absorbsi selanjutnya dianalisis dan dibandingkan dengan kontrol tanpa perlakuan, dan baku mutu yang dipersyaratkan oleh KLH (2014) melalui Peraturan Menteri Lingkungan Hidup (PERMENLH) No. 5/2014 yaitu pH, Biochemical Oxygen Demand (BOD), Chemical Oxygen Demand (COD), dan Total Suspended Solid (TSS), serta Kemenkes (2017) melalui
Peraturan Menteri Kesehatan (PERMENKES) No. 32/2017 yaitu $\mathrm{pH}$, turbiditas, warna, Total Dissolved Solids (TDS), bakteri E. Coli, serta total coliform.

\section{Analisis teknik, ekonomi, dan lingkungan}

Analisis teknik menjelaskan secara deskriptif mengenai kemudahan dari sisi proses produksi, bahan yang digunakan, peralatan, teknologi, dan tenaga kerja pada perusahaan (Indrasti dan Fauzi 2009). Analisis secara ekonomi dilakukan dengan memperkirakan kemungkinan penghematan, keuntungan yang diperoleh, serta estimasi biaya yang dikeluarkan dari teknik produksi bersih yang diterapkan (Haryono 2016). Analisis lingkungan dilakukan dengan memperhitungkan dampak atau manfaat yang didapat dari adanya penerapan produksi bersih (UNEP 2000), seperti pengurangan limbah dari segi kuantitas (Purwanto 2009), atau pengurangan penggunaan sumberdaya (UNEP dan APINI 2008).

\section{HASIL DAN PEMBAHASAN pencucian udang} Karakteristik awal air limbah

Sampel yang digunakan dalam penelitian adalah sampel air limbah pencucian bahan baku udang yang diambil pada saat proses produksi berlangsung. Hasil analisis terhadap karakteristik air limbah pencucian udang dapat dilihat pada Tabel 1 .

Berdasarkan hasil analisis yang ditunjukkan pada Tabel 1, kualitas air limbah pencucian udang belum dapat

Tabel 1 Karakteristik awal air limbah pencucian udang

(Table 1 Initial characteristics of shrimp washing wastewater)

\begin{tabular}{|c|c|c|c|}
\hline $\begin{array}{l}\text { Parameter/ } \\
\text { (Parameter) }\end{array}$ & $\begin{array}{c}\text { Satuan/ } \\
\text { (Unit) }\end{array}$ & $\begin{array}{c}\text { Hasil uji/ } \\
\text { (Test results) }\end{array}$ & $\begin{array}{c}\text { Baku mutu air limbah* } \\
\text { (PERMENLH No. 5/2014)/ } \\
\text { (Quality standards of wastewater (Regulation of } \\
\text { Ministry of Environment Republic of Indonesia } \\
\text { No. 5/2014)) }\end{array}$ \\
\hline $\mathrm{pH} / \mathrm{pH}$ & - & 7.15 & $6-9$ \\
\hline Suhu/Temperature & ${ }^{\circ} \mathrm{C}$ & 27.0 & - \\
\hline TSS/TSS & $\mathrm{mg} / \mathrm{L}$ & 106 & 30 \\
\hline $\mathrm{BOD} / B O D$ & $\mathrm{mg} / \mathrm{L}$ & 198.00 & 100 \\
\hline $\mathrm{COD} / \mathrm{COD}$ & $\mathrm{mg} / \mathrm{L}$ & 694.41 & 200 \\
\hline
\end{tabular}


memenuhi baku mutu yang dipersyaratkan oleh Pemerintah. Hal ini dapat dilihat dari hasil analisis terhadap parameter TSS, BOD, dan COD yang tinggi dan melebihi baku mutu. Air limbah pencucian udang pada dasarnya dapat diolah menjadi air bersih, dan dapat digunakan kembali untuk menambah pasokan dan memenuhi kebutuhan air di dalam industri pengolahan udang, namun hal tersebut membutuhkan sejumlah treatment atau perlakuan. Perlakuan yang dapat dilakukan pada penelitian ini adalah melalui proses koagulasi-flokulasi dan dapat dilanjutkan dengan proses absorbsi maupun filtrasi. Salah satu bahan koagulan yang dipilih adalah biokoagulan kitosan. Menurut Suptijah (2012), apabila kitosan dilarutkan dalam asam maka akan menjadi polimerkationik dengan struktur linier sehingga kitosan dapat digunakan dalam proses flokulasi, pembentuk film atau imobilisasi dalam beberapa agen biologi termasuk enzim.

\section{Konsentrasi optimum larutan kitosan}

Renault et al. (2009) menyebutkan bahwa kitosan banyak digunakan dalam pengolahan air dan air limbah karena dapat dikondisikan dan digunakan untuk kompleks pencemar dalam berbagai bentuk, mulai dari bentuk terlarut dalam air hingga bentuk padatan. Hasil konsentrasi larutan kitosan optimum yang diperoleh ditunjukkan pada Tabel 2.

Berdasarkan hasil uji warna pada Tabel 2 diketahui bahwa konsentrasi larutan kitosan yang optimum bila dibandingkan dengan kontrol adalah larutankitosan padakonsentrasi 15 ppm. Hasil uji dari percobaan penambahan

Tabel 2 Penentuan konsentrasi larutan kitosan optimum

(Table 2 Determination of concentration of the optimum chitosan solution)

\begin{tabular}{ccc}
\hline $\begin{array}{c}\text { Konsentrasi larutan kitosan/ } \\
\begin{array}{c}\text { Concentration of chitosan solution } \\
(\mathrm{ppm})\end{array}\end{array}$ & $\begin{array}{c}\text { Hasil uji warna/ } \\
\text { Color test results } \\
\text { (TCU) }\end{array}$ & $\begin{array}{c}\text { Hasil uji pH/ } \\
\text { pH test results }\end{array}$ \\
\hline $\begin{array}{c}\text { Kontrol/Control } \\
5\end{array}$ & $\begin{array}{c}105.00 \pm 5.66 \\
10\end{array}$ & $7.04 \pm 0.02$ \\
15 & $74.50 \pm 12.02$ & $7.60 \pm 0.08$ \\
20 & $102.00 \pm 15.56$ & $7.36 \pm 0.79 \pm 0.05$ \\
25 & $128.50 \pm 23.33$ & $7.21 \pm 0.01$ \\
Baku Mutu Air Bersih ${ }^{\star}\left(Q^{*}\right.$ uality & 50 & $6.5-8.5$ \\
standards of clean water ${ }^{*}$ & & \\
${ }^{*}$ Kemenkes (2017) & &
\end{tabular}

Tabel 3 Penentuan konsentrasi larutan kitosan pada percobaan kedua (Table 3 Determination of the chitosan solution concentration in the second experiment)

\begin{tabular}{|c|c|c|c|c|}
\hline $\begin{array}{c}\text { Konsentrasi larutan } \\
\text { kitosan/Concentration of } \\
\text { chitosan solution ( } \mathrm{ppm})\end{array}$ & $\begin{array}{l}\text { Hasil uji turbiditas/ } \\
\text { Turbidity test results } \\
\text { (NTU) }\end{array}$ & $\begin{array}{c}\text { Hasil warna / } \\
\text { Colour test results } \\
\text { (TCU) }\end{array}$ & $\begin{array}{l}\text { Hasil uji TDS / } \\
\text { TDS test results } \\
\text { (ppm) }\end{array}$ & $\begin{array}{l}\text { Hasil uji } \mathrm{pH} / \\
\text { pH test results }\end{array}$ \\
\hline Kontrol/Control & $50.50 \pm 0.71$ & $282.5 \pm 0.71$ & $572.50 \pm 7.78$ & $7.15 \pm 0.01$ \\
\hline 15 & $8.91 \pm 0.08$ & $84.00 \pm 1.41$ & $525.50 \pm 7.78$ & $7.34 \pm 0.11$ \\
\hline $15+5$ & $13.99 \pm 0.11$ & $92.00 \pm 4.24$ & $530.00 \pm 15.56$ & $7.55 \pm 0.02$ \\
\hline $15+10$ & $10.04 \pm 0.02$ & $60.00 \pm 0.00$ & $527.00 \pm 4.95$ & $7.54 \pm 0.01$ \\
\hline $15+15$ & $8.67 \pm 0.81$ & $49.50 \pm 0.71$ & $514.50 \pm 4.95$ & $7.54 \pm 0.01$ \\
\hline $15+20$ & $10.61 \pm 0.60$ & $63.00 \pm 1.41$ & $526.50 \pm 7.78$ & $7.47 \pm 0.01$ \\
\hline $\begin{array}{l}\text { Baku Mutu Air Bersih* } \\
\text { (Quality standards of } \\
\left.\text { clean } \text { water }^{\star}\right)\end{array}$ & 25 & 50 & 1000 & $6.5-8.5$ \\
\hline
\end{tabular}


larutan kitosan 15 ppm dengan sekali proses ternyata belum dapat memenuhi persyaratan baku mutu pada PERMENKES No. 32/2017, oleh karena itu percobaan dilanjutkan dengan melakukan percobaan kedua (dua kali proses). Hasil dengan menggunakan percobaan kedua dapat dilihat pada Tabel 3. Hasil analisis pada Tabel 3 menunjukkan bahwa penambahan larutan kitosan dengan dua kali proses yaitu penggunaan larutan kitosan dengan konsentrasi 15 ppm pertama ditambah dengan konsentrasi 15 ppm kedua (15 ppm +15 ppm) memiliki hasil yang lebih baik dibandingkan dengan satu kali proses. Hal ini dapat ditunjukkan dengan adanya penurunan tingkat turbiditas, warna, dan TDS. Hasil pada Tabel 3 juga dapat memenuhi baku mutu yang telah dipersyaratkan Pemerintah yaitu PERMENKES No. 32/2017.

Kitosan memiliki beberapa karakteristik intrinsik yang membuatnya menjadi koagulan dan/atau flokulan yang efektif untuk menghilangkan kontaminan dalam keadaan terlarut, yaitu densitas muatan kationik tinggi, rantai polimer panjang, penghubung agregat dan pengendapan (dalam kondisi $\mathrm{pH}$ netral atau alkalin) (Renault et al. 2009). Koagulan dalam proses koagulasiflokulasi berfungsi untuk mempercepat pembentukan flok yang lebih besar, kokoh dan stabil (Joko et al. 2016). Koagulasi adalah penambahan dan pengadukan cepat (flash mixing) dengan koagulan yang bertujuan untuk mendestabilisasi partikel-partikel koloid dan suspended solid, sedangkan flokulasi merupakan pengadukan lambat yang mengiringi disperse koagulan. Tujuan flokulasi adalah mempercepat tumbukan yang menyebabkan terjadinya gumpalan partikel koloid yang tidak stabil sehingga dapat diendapkan (Nugraheni et al. 2014).

Tabel 4 Hasil uji perbandingan sampel dengan baku mutu

(Table 4 The result of comparison test of samples with the quality standard)

\begin{tabular}{|c|c|c|c|c|c|}
\hline Parameter/(Parameter) & $\begin{array}{l}\text { Kontrol/ } \\
\text { (Control) }\end{array}$ & $\begin{array}{l}\text { Larutan } \\
\text { kitosan }^{\text {a }} \\
(\text { Chitosan } \\
\left.\text { solution }^{a}\right)\end{array}$ & $\begin{array}{l}\text { Larutan } \\
\text { kitosan }^{\text {b }} \\
(\text { Chitosan } \\
\left.\text { solution }^{b}\right)\end{array}$ & $\begin{array}{l}\text { Baku mutu } \\
\text { air limbah }{ }^{*} \\
(\text { Quality } \\
\text { standards of } \\
\left.\text { wastewater }^{\star}\right) \\
\end{array}$ & $\begin{array}{c}\text { Baku mutu } \\
\text { air bersih }{ }^{* *} / \\
(\text { Quality stan- } \\
\text { dards for clean } \\
\left.\text { water }^{* *}\right)\end{array}$ \\
\hline $\mathrm{BOD} / B O D(\mathrm{mg} / \mathrm{L})$ & 198.00 & 97.50 & 47.00 & 100 & - \\
\hline $\mathrm{COD} / \mathrm{COD}(\mathrm{mg} / \mathrm{L})$ & 692.41 & 162.66 & 99.37 & 200 & - \\
\hline TSS/TSS (mg/L) & 106 & 30 & 41 & 100 & - \\
\hline $\mathrm{pH} / p H$ & 7.15 & 7.55 & 7.96 & $6-9$ & $6,5-8,5$ \\
\hline Suhu/ Temperature $\left({ }^{\circ} \mathrm{C}\right)$ & 27.0 & 27.3 & 28.0 & - & $\begin{array}{l}\text { Suhu udara } \\
\pm 3^{\circ} \mathrm{C} / \text { Air } \\
\text { temperature } \\
\quad \pm 3^{\circ} \mathrm{C}\end{array}$ \\
\hline $\begin{array}{l}\text { Kekeruhan/Turbidity } \\
\text { (NTU) }\end{array}$ & 51 & 6.21 & 5.73 & - & 25 \\
\hline Warna/Color (TCU) & 283 & 54 & 42 & - & 50 \\
\hline TDS/TDS (ppm) & 578 & 507 & 518 & - & 1000 \\
\hline $\begin{array}{l}\text { E coli/ E. coli (CFU/100 } \\
\mathrm{ml})\end{array}$ & 0 & 0 & 0 & - & 50 \\
\hline $\begin{array}{l}\text { Total coliform/ } \\
\text { Total coliform (CFU/100 } \\
\mathrm{ml})\end{array}$ & TBUD & 0 & 0 & - & 0 \\
\hline $\begin{array}{l}\text { "Larutan kitosan } 15 \mathrm{ppm}+15 \\
\text { bLarutan kitosan } 15 \mathrm{ppm}+15 \\
\text { (Chitosan solution of } 15 \mathrm{ppm} \\
{ }^{\star} \mathrm{KLH}(2014) \\
{ }^{*} \text { Kemenkes }(2017)\end{array}$ & $\begin{array}{l}\mathrm{m} / \text { (Chitosa } \\
\mathrm{m}+\text { kitosan } \\
15 \mathrm{ppm}+\mathrm{ch}\end{array}$ & $\begin{array}{l}\text { solution of } 15 \\
\text { erpihan } 15 \text { gra } \\
\text { san flakes } 15\end{array}$ & $\begin{array}{l}\mathrm{ppm}+15 \mathrm{p} \\
\mathrm{n} / \\
\mathrm{ram})\end{array}$ & & \\
\hline
\end{tabular}




\section{Hasil analisis dari proses absorbsi}

Proses koagulasi flokulasi dengan dua kali proses selanjutnya dilakukan percobaan penambahan perlakuan, yaitu dengan proses absorbsi yang ditujukan untuk mendapatkan hasil yang lebih optimal dan diharapkan dapat memenuhi kriteria air minum. Proses absorbsi dilakukan pada sampel yang telah diberikan larutan kitosan optimum dengan dua kali proses, telah disaring, dan telah dialirkan pada kolom dari pipa plastik berisi kitosan serpihan. Sampel hasil proses absorbsi selanjutnya dibandingkan dengan sampel hasil tanpa proses absorbsi, kontrol, serta baku mutu yang dipersyaratkan. Hasil uji tersebut ditunjukkan pada Tabel 4.

Berdasarkan Tabel 4 diketahui bahwa sampel hasil penambahan proses absorbsi menggunakan kolom kitosan serpihan menunjukkan hasil yang lebih baik bila dibandingkan dengan sampel tanpa proses absorbsi dan kontrol, terutama untuk parameter BOD, COD, tingkat kekeruhan, warna, dan total coliform. Suptijah (2012) menjelaskan bahwa kitosan memiliki kegunaan yang cukup luas dan mapan dalam pengolahan air limbah. Kitosan serbuk atau serpihan mempunyai sifat-sifat rendah akan porositas, jarak antar lapisan polimernya rendah, sehingga mekanisme difusinya menjadi rendah (difusi eksternal maupun difusi antar partikel) (Suptijah 2012).

Berdasarkan hasil perbandingan antara kontrol dengan sampel yang diberi perlakuan menunjukkan bahwa penggunaan larutan kitosan 15 ppm dengan dua kali proses dan dilanjutkan dengan proses absorbsi menggunakan kitosan serpihan 15 gram dapat menurunkan parameter kualitas air limbah 73\% (BOD), 86\% (COD), dan $61 \%$ (TSS). Kitosan juga efektif dalam menjernihkan air. Hal tersebut ditunjukkan melalui adanya penurunan kekeruhan $89 \%$, warna $85 \%$, TDS $10 \%$, serta jumlah bakteri coliform yang semula TBUD menjadi 0 . Penurunan total bakteri akibat adanya penggunaan kitosan dikarenakan molekul kitosan memiliki kemampuan untuk berinteraksi dengan permukaan bakteri dan teradsorpsi pada permukaan sel dan menumpuk pada permukaan sel mikroba dan membentuk lapisan pertahanan di sekitar sel (Al-Manhel et al. 2018). Hasil pada Tabel 4 juga menunjukkan bahwa penggunaan kitosan dapat memenuhi baku mutu yang dipersyaratkan oleh pemerintah.

\section{Hasil analisis teknik, ekonomi, dan lingkungan}

Kitosan secara teknik merupakan salah satu bahan koagulan alami yang cukup efektif dalam menjernihkan air. Air hasil daur ulang yang diperoleh dari penelitian ini dapat memenuhi kriteria air bersih seperti yang ditetapkan oleh pemerintah, oleh karena itu air hasil daur ulang dapat digunakan kembali oleh industri untuk kegiatan yang tidak bersentuhan dengan produk. Menurut Rahmani (2015), air bersih yang diperoleh dari hasil daur ulang dapat digunakan untuk flushing toilet, cooling towers, air umpan boiler, evaporator, atau digunakan untuk sanitasi lantai di luar area proses produksi. Industri yang menghendaki air hasil daur ulang dapat digunakan kembali untuk kegiatan proses produksi dan bersentuhan dengan produk, maka percobaan ini membutuhkan kajian lebih mendalam agar air daur ulang dapat memenuhi standar/kriteria air yang dipersyaratkan. Persyaratan air yang akan digunakan untuk proses produksi pada industri makanan (termasuk industri pengolahan hasil perikanan) harus memenuhi kriteria/standar air minum (sesuai dengan persyaratan dari Uni Eropa yaitu Council Directive CD/98/83/EC on the quality of water intended for human consumption).

Hasil percobaan daur ulang yang dilakukan pada penelitian ini selanjutnya dilakukan perhitungan secara ekonomi untuk mengukur tingkat kelayakan, keuntungan yang didapat, serta jangka waktu pengembalian atas investasi yang dikeluarkan oleh suatu industri. Proses daur ulang dengan menggunakan kitosan membutuhkan biaya investasi awal yang terdiri atas biaya produksi kitosan, serta biaya instalasi dan operasional daur ulang.

Biaya produksi kitosan terdiri atas harga prototype/peralatan pembuatan kitosan senilai Rp. 15.000.000/3 tahun atau Rp.18.939/ hari, serta bahan-bahan pembuatan kitosan 


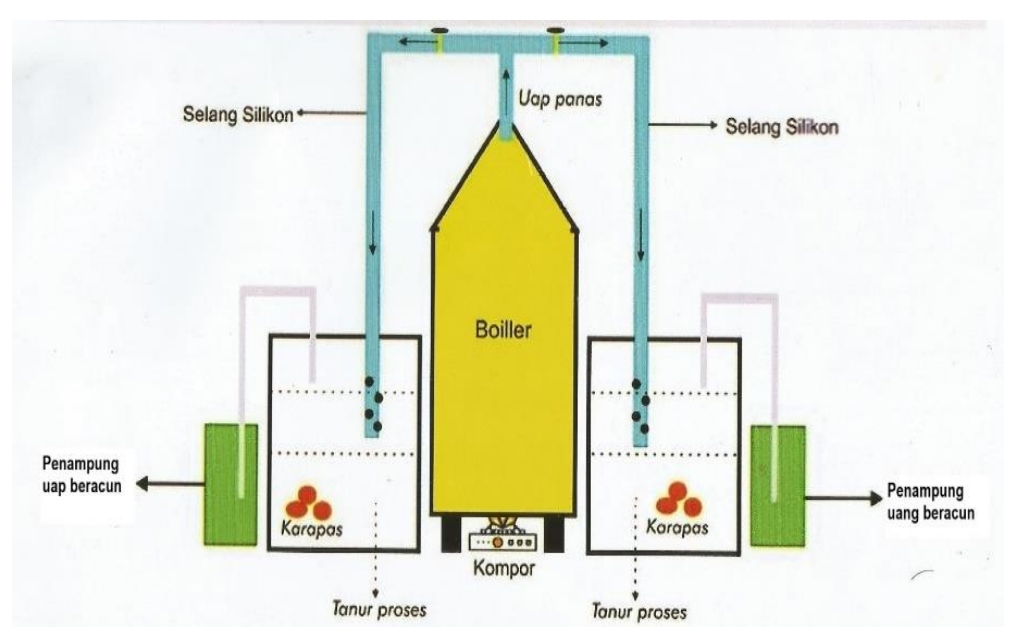

Gambar 2 Prototype pembuatan kitosan (Suptijah 2017).

(Figure 2 Prototype of the making of chitosan (Suptijah 2017).

per hari (terdiri atas $\mathrm{HCl} 1 \mathrm{~N}$ Rp. 504.000/70 L, NaOH 3 N Rp 150.000/3 kg, NaOH 50\% Rp 625.000, akuades dan gas Rp. 262.000, sehingga total harga adalah Rp 1.541.000/hari). Total biaya produksi adalah Rp. 1.559.939/ hari. Prototype/peralatan pembuatan kitosan seperti pada Gambar 2 dapat menghasilkan $3 \mathrm{~kg}$ kitosan/hari dari bahan baku karapas sebanyak $20 \mathrm{~kg}$, sehingga total biaya produksi adalah (Rp. 1.559.939/hari: $3 \mathrm{~kg} / \mathrm{hari})=$ Rp. $519.980 / \mathrm{kg} /$ hari.

Biaya instalasi terdiri atas peralatan yang diperlukan untuk melakukan proses daur ulang yaitu, bak fiber Rp 1.400.000, tangki flokulasi Rp. 70.000.000, dan pipa paralon Rp 2.682.300. Total biaya instalasi alat daur ulang adalah senilai Rp. 73.382.300/20 tahun atau Rp. 10.148/hari. Biaya proses daur ulang terdiri atas bahan-bahan yang digunakan dalam melakukan proses daur ulang, yaitu kitosan yang diperoleh dari hasil pembuatan dengan prototype, serta asam asetat sebagai bahan pelarut kitosan dengan total harga Rp. 696.928/hari.

Volume air limbah pencucian udang di industri pengolahan udang di Pati Jawa Tengah adalah sebesar $273 \mathrm{~m}^{3} /$ hari, sedangkan air limbah pencucian yang akan didaur ulang adalah sebesar $60 \mathrm{~m}^{3} /$ hari. Kebutuhan air pada industri pengolahan tersebut secara keseluruhan dipasok dari air PDAM dengan harga air Rp. $12.850 / \mathrm{m}^{3}$. Kitosan yang digunakan sebagai biokoagulan dalam daur ulang air pada industri pengolahan tersebut dapat menghemat pembelian air sebesar Rp. $12.850 / \mathrm{m}^{3}$ x $60 \mathrm{~m}^{3} / \mathrm{hari}=771.000 /$ hari. Kitosan yang diproduksi juga dapat menghasilkan keuntungan lain bagi perusahaan, yaitu apabila kitosan dijual di pasaran maka perusahaan akan menghasilkan keuntungan Rp. 1.440.060/hari.

Analisis ekonomi lebih lanjut dilakukan dengan menghitung $\mathrm{B} / \mathrm{C}$ Ratio dan jangka waktu pengembalian atas investasi yang dilakukan (payback periode/PBP). Analisis Net benefit-cost ratio (B/C Ratio) digunakan untuk menilai tingkat efisiensi setiap rupiah yang dikeluarkan (cost) yang diperoleh dari penerimaan (benefit) (Indrasti dan Fauzi 2009). Nilai B/C Ratio > 1 maka proyek dinyatakan layak dan dapat dilaksanakan, sedangkan nilai $\mathrm{B} / \mathrm{C}=1$ maka proyek bisa dilaksanakan atau tidak bisa, dan apabila nilai $\mathrm{B} / \mathrm{C}<1$ maka proyek tidak layak untuk dilaksanakan. Analisis PBP menurut Manope et al. (2014) dihitung dengan cara membagi total investasi dengan keuntungan yang diperoleh. Berikut perhitungan $\mathrm{B} / \mathrm{C}$ Ratio dan PBP :

$$
\text { BC Ratio }=\frac{(\text { Rp 771.000/hari }+ \text { Rp 1.440.060/hari })}{(\text { Rp 519.980/hari }+ \text { Rp. 10.148/hari + Rp 696.928/hari })}=1,80
$$

Payback Periode $(\mathrm{PBP})=\frac{\text { Rp } 15.000 .000+\text { Rp. } 73.382 .300}{\text { Rp. } 771.000 / \text { hari }}=114.6$ hari $=4$ bulan

Berdasarkan perhitungan diatas diketahui bahwa nilai $\mathrm{B} / \mathrm{C}$ Ratio menunjukkan nilai $>1$, maka teknik daur ulang air limbah layak untuk dilaksanakan dengan PBP 114,6 
hari atau 4 bulan. Pemanfaatan kitosan untuk daur ulang juga dapat memberikan keuntungan bagi lingkungan, antara lain mengolah limbah padat menjadi bahan yang lebih bermanfaat, menghemat penggunaan sumberdaya air, menambah pasokan air, mengurangi volume pembelian air (bila sumber air didapat dari perusahaan penyedia air minum), dan mengurangi volume limbah cair pada tampungan instalasi pengolahan air limbah (IPAL). Daur ulang yang dilakukan oleh suatu industri juga dapat turut serta menjaga sumberdaya alam dan pengelolaan lingkungan, sehingga dapat menciptakan industri berbasis green industry.

\section{KESIMPULAN}

Proses daur ulang dengan teknik biokoagulan kitosan efektif mengubah air limbah pencucian udang menjadi air bersih. Konsentrasi optimum larutan kitosan yang diperoleh adalah 15 ppm dengan dua kali proses, yang dilanjutkan dengan proses absorbsi dengan kitosan serpihan seberat 15 gram. Tingkat efektifitas dapat dilihat dari adanya penurunan BOD 73\%, COD 86\%, TSS $61 \%$, kekeruhan $89 \%$, warna $85 \%$, TDS $10 \%$, dan menurunkan total bakteri coliform yang semula TBUD (melebihi batas persyaratan) menjadi 0. Penggunaan biokoagulan kitosan juga layak diterapkan secara ekonomi dimana nilai B/C Ratio yang diperoleh sebesar 1,86 atau lebih besar dari 1, dan memiliki nilai jangka waktu pengembalian investasi (Payback Periode) selama 4 bulan.

\section{DAFTAR PUSTAKA}

Abdullah A, Suptijah P, Suwandi R. 2008. Karakteristik fisik dan kimia agar bakto dengan penambahan kitosan. Buletin Teknologi Hasil Perikanan. 11(1) :28-39.

Alkaya E, Demirer GN. 2016. Minimizing and adding value to seafood processing waste. Journal of Food and Bioproducts Processing. 100(A): 195-202.

Al-Manhel AJ, Al-Hilphy ARS, Niamah AK. 2018. Extraction of chitosan, characterisation and its use for water purification. Journal of the Saudi Society of Agricultural Sciences. 17(2): 186-190.
Barbusinski K, Salwiczek S, Paszewska A. 2016. The use of chitosan for removing selected pollutan from water and waste water short review. Architecture Civil Engineering. 2(9): 107-115.

Cassani S, Leth T, Knochel S. 2006. Water reuse in a shrimp processing line : safety considerations using a HACCP approach. Journal Food Control. 17: 540-550.

Chowdhury P, Viraraghavan T, Srinivisan A. 2010. Biological treatment processes for fish processing wastewater-a review. Bioresources Technology. 101(2): 439-449.

[CD] Council Directive 98/83/EC. 1998. The Quality of Water Intended for Human Consumption. Official Journal of the European Communities : The Council of The European Union.

Garcia MA, Montelongo I, Rivero A, de la Paz $N$, Fernandez $M$, de Villavicencio $M N$. 2016. Treatment of wastewater from fish processing industry using chitosan acid salts. International Journal of Water and Waste Water Treatment. 2(2): 1-6.

Haryono AT. 2016. Analisis penerapan produksi bersih industri kertas (Studi kasusdi PT Pindo-Deli Pulp and Paper Mills Indonesian unit Paper Machine 4). [Skripsi]. Bogor (ID): Institut Pertanian Bogor.

Hendrawati, Sumarni S, Nurhasni. 2015. Penggunaan kitosan sebagai koagulan alami dalam perbaikan kualitas air danau. Jurnal Kimia VALENSI. 1(1): 1-11.

Hidayat T, Suptijah P, Nurjanah. 2013. Karakteristik tepung buah lindur (Brugeira gymnorrhiza) sebagai beras analog dengan penambahan sagu dan kitosan. Jurnal Pengolahan Hasil Perikanan Indonesia. 16(3): 268-277.

Ibrahim B, Suptijah P, Zahid A. 2012. Efektivitas kitosan mikrokristalin sebagai alternatif antibakteri alami dalam mouth wash. Jurnal Pengolahan Hasil Perikanan Indonesia. 15(2): 119-126.

Indrasti NS, Fauzi AM. 2009. Produksi Bersih. Bogor (ID): IPB Pr.

Joko T, Putri DAC, Dangiran HL. 2016. Chitosan on reducing chemical oxygen demands in laundry waste water. 
International Journal of Sciences. 30(1): 104-111.

[Kemenkes] Kementerian Kesehatan. 2017. Peraturan Menteri Kesehatan Republik Indonesia Nomor 32/MENKES/PER/ IV/2017 tentang standar baku mutu kesehatan lingkungan dan persyaratan air untuk keperluan higiene sanitasi, kolam renang, solus per aqua, dan pemandian umum. Jakarta (ID): Kementerian Kesehatan.

[KLH] Kementerian Lingkungan Hidup. 2014. Peraturan Menteri Lingkungan Hidup Republik Indonesia Nomor 5 Tahun 2014 tentang Baku mutu air limbah. Jakarta (ID): Kementerian Lingkungan Hidup.

Li A, Lin R, Lin C, He B, Zheng T, Lu L, Cao Y. 2016. An environment-friendly and multi-functional absorbent from chitosan for organic pollutants and heavy metal ion. Carbohydrate Polymers. 148: 272-280.

Manope BF, Kindangen P, Tawas H. 2014. Analisa kelayakan usaha komoditas biji dan fuli pala melalui penilaian aspek finansial pada pedagang pengumpul "Kios Chandra" di Pulau Siau. Jurnal Riset Ekonomi Manajemen Bisnis dan Akuntansi. 2(4): 320-330.

Mathukumaran S. Baskaran K. 2013. Organic and nutrient reduction in a fish processing facility-A case study. International Biodeterioration and Biodegradation. 85: 563-570.

[MIWEA] Michigan Water Environment Association. 2018. Procedure for Laboratory Jar Test. [internet]. [diunduh 2018 Agustus 9]. Tersedia dari: https:// www.mi-wea.org/docs/Official\%20 Proced.\% 20 for $\% 20$ Laboratory $\% 20$ Jar\%20Test\%204-15.pdf

Muruganandam L, Kumar MPS, Jena A, Gulla S, Godhwani B. 2017. Treatment of waste water by coagulation and flocculation using biomaterials. IOP Conf. Series: Materials Science and Engineering. 263: 1-11.

Nilsson L, Persson P, Ryden L, Darozhka S, Zaliauskiene A. 2007. Environmental Management, Book 2. Stockholm (SE): Baltic University Pr.
Nugraheni DT, Sudarno, Hadiwidodo M. 2014. Cangkang udang sebagai biokoagulan untuk penyisihan turbidity, TSS, BOD dan COD pada pengolahan air limbah farmasi PT. Phapros Tbk, Semarang. Jurnal Teknik Lingkungan. 3(4): 1-10.

Nurilmala M, Suptijah P, Nurfianti D. 2007. Penggunaan kitosan sebagai pembentuk gel pada bakso ikan kurisi (Nemipterus nematophorus). Buletin Teknologi Hasil Perikanan. 10(1): 35-46.

Pontius FW. 2016. Chitosan as a drinking water treatment coagulant. American Journal of Civil Engineering. 4(5): 205-215.

Prayudi T, Susanto JP. 2000. Chitosan sebagai bahan koagulan limbah cair industri tekstil. Jurnal Teknologi Lingkungan. 1(2): 121-125.

Purwanto. 2009. Penerapan teknologi produksi bersih untuk meningkatkan efisiensi dan mencegah pencemaran industri. Pidato pengukuhan pada Upacara Penerimaan Jabatan Guru Besar dalam Ilmu Teknik Kimia Fakultas Teknik Universitas Diponegoro 22 Januari 2009. Semarang (ID): Universitas Diponegoro.

Rahmani A. 2015. Pengelolaan air dalam industri pangan [internet]. [diunduh 2017 Maret 5]. Tersedia dari : http//www. researchgate.net/publication/287583632.

Renault F, Sancey B, Badot PM, Crini G. 2009. Chitosan for coagulation/flocculation processes - An eco-friendly approach. European Polymer Journal. 45(2009): 1337-1348.

Rochima E. 2007. Karakterisasi kitin dan kitosan asal limbah rajungan Cirebon Jawa Barat. Buletin Teknologi Hasil Perairan. 10(1): 9-22.

Sinardi, Soewondo P, Notodarmojo S. 2013. Pembuatan karakterisasi dan aplikasi kitosan dari cangkang kerang hijau (Mytulus viridis linneaus) sebagai koagulan penjernih air. Konferensi Nasional Teknik Sipil 7 (KoNTekS7). L33-L38.

Sugita P, Wukirsari T, Sjahriza A, Wahyono D. 2009. Kitosan Sumber Biomaterial Masa Depan. Bogor (ID): IPB Pr.

Suprihatin, Romli M. 2009. Pendekatan produksi bersih dalam industri pen- 
golahan ikan: Studi kasus industri penepungan ikan. [internet]. [diunduh 2018 Agustus 9]. Tersedia dari: https:// repository.ipb.ac.id/bitstream/handle/123456789/40397/Pendekatan\%20 Produksi\%20Bersih.pdf? sequence $=4 \&$ isAllowed $=\mathrm{y}$

Suptijah P, Zahiruddin W, Firdaus D. 2008. Pemurnian air sumur dengan kitosan melalui tahapan koagulasi dan filtrasi. Buletin Teknologi Hasil Perikanan. 11(1): 65-72.

Suptijah P, Jacoeb AM, Rachmania D. 2011. Karakterisasi nano kitosan cangkang udang vannamei (Litopenaeus vannamei) dengan metode gelasi ionik. Jurnal Pengolahan Hasil Perikanan Indonesia. 14(2):78-84.

Suptijah P. 2012. Pengembangan kitosan sebagai absorben pengotor dalam aplikasi pemurnian agar dan karagenan. [Disertasi]. Bogor (ID): Institut Pertanian Bogor.

[UNEP and APINI] United Nations Environment Programme and Institute of Environmental Engineering Kaunas University of Technology Lithuania. 2008. Introduction to cleaner production (CP) concepts and practice [internet]. [diunduh 2017 Juni 4]. Tersedia dari: http//www.un.org/esa/sustdev/sdissues/ technology/cleanerproduction.pdf.

[UNEP] United Nations Environment Programme. 2000. Cleaner Production Assessment in Fish Processing. United States (US): UNEP.

Wahyuni S, Khaeruni A, Hartini. 2013. Kitosan cangkang udang windu sebagai pengawet fillet ikan gabus (Channa striata). Jurnal Pengolahan Hasil Perikanan Indonesia. 16(3): 233-241.

Wardhani K, Widyastuti, Hadiwidodo M, Sudarno. 2014. Khitin cangkang rajungan (Portunus pelagicus) sebagai biokoagulan untuk penyisihan turbidity, TSS, BOD dan COD pada pengolahan air limbah farmasi PT. Phapros Tbk, Semarang. Jurnal Teknik Lingkungan. 3(4): 1 - 6.

Zahiruddin W, Ariesta A, Salamah E. 2008. Karakteristik mutu dan kelautan kitosan dari ampas silase kelapa udang windu (Penaeus monodon). Buletin Teknologi Hasil Perairan. 11(2):140-151.

Zahiruddin W, Erungan AC, Wiraswanti I. 2008. Pemanfaatan karagenan dan kitosan dalam pembuatan bakso ikan kurisi (Nemipterus nematophorus) pada penyimpanan suhu dingin dan beku. Buletin Teknologi Hasil Perikanan. 11(1): 40-52. 